\title{
BK Virus Associated Nephropathy, a Cause of Early Renal Allograft Dysfunction: A Single Centre Study Shrestha $\mathrm{S},{ }^{1}$ Kerr PG, ${ }^{2}$ Kanellis J, ${ }^{2}$ Polkinghorne KR, ${ }^{2}$ Brown F, ${ }^{2}$ Yii M, ${ }^{3}$ Mulley $\mathrm{W}^{2}$
}

${ }^{1}$ Department of Internal Medicine,

Nobel Medical College and Teaching Hospital, Biratnagar, Nepal.

${ }^{2}$ Department of Nephrology,

Monash Medical Centre, and Department of Medicine, Monash University,

Melbourne, Australia.

${ }^{3}$ Department of Vascular Surgery,

Monash Medical Centre, Melbourne, Australia.

\section{Corresponding Author}

Shailendra Shrestha,

Department of Internal Medicine,

Nobel Medical College and Teaching Hospital, Biratnagar, Nepal.

International Society of Nephrology (ISN) fellow at Department of Nephrology, Monash Medical Centre, Melbourne, Australia.

E-mail: shailendra_1975@hotmail.com

\section{Citation}

Shrestha S, Kerr PG, Kanellis J, Polkinghorne KR, Brown F, Yii M, et al. BK Virus Associated Nephropathy, a Cause of Early Renal Allograft Dysfunction: A Single Centre Study. Kathmandu Univ Med J 2015;50(2):140-5.

\begin{abstract}
Background

BK virus associated nephropathy (BKVN) is an important cause of early graft dysfunction in renal transplant recipients. The present study was carried out to determine the burden of BKVN in a single renal transplant centre in Australia.
\end{abstract}

\section{Method}

A retrospective analysis of de novo renal transplant recipients from 2010 to 2013 was performed to identify biopsy proven BKVN. Estimated glomerular filtration rate (eGFR) was compared at baseline, at BKVN diagnosis and 3 and 12 months postdiagnosis.

Result

Of the 317 de novo renal transplants recipients in the study period, 20 (6.3\%) developed BKVN. The mean age was $54.8 \pm 13.1$ years and $13(65 \%)$ were male. The mean time from transplant to BKVN was $8.7 \pm 6.7$ months with 17 (85\%) diagnosed within 12 months. Four recipients each were diagnosed BKVN on 3 and 12 month surveillance biopsy. Six (30\%) had normal eGFR at diagnosis. Mean eGFR at diagnosis was $38.8 \pm 19.2 \mathrm{ml} / \mathrm{min} / 1.73 \mathrm{~m}^{2}$, which was significantly lower $(\mathrm{p}<0.01)$ than that at baseline $\left(50.3 \pm 16.4 \mathrm{ml} / \mathrm{min} / 1.73 \mathrm{~m}^{2}\right)$. eGFR improved numerically at 3 and 12 months post-diagnosis, however the difference was not significant. One patient had graft failure, 19 months after diagnosis.

\section{Conclusion}

BKVN generally occurs in first post-transplant year and is an important cause of early graft dysfunction. Surveillance biopsy helps in detecting subclinical BKVN.

\section{KEY WORDS}

Immunosuppression, renal transplant, surveillance biopsy. 


\section{INTRODUCTION}

$B K$ virus (BKV) is a ubiquitous, double-stranded DNA virus that is member of the human polyomavirus family. Its name "BK" originated from the initials of a renal transplant recipient (RTR), in whom it was first detected in $1971 .{ }^{1}$ According to the seroprevalance studies, the virus affects $80-90 \%$ of the children in first 10 years of life, as a primary asymptomatic infection. ${ }^{2}$ Subsequently, BKV goes to a latent state in renal tubular epithelium.

In RTRs, because of the profound immunosuppression BKV may reactivate and present as asymptomatic viruria, viremia, and BK virus associated nephropathy (BKVN) in up to $40 \%, 20 \%$ and $10 \%$ of RTRs respectively. ${ }^{3} 50 \%$ of the RTRs who develop BKV viremia, do so within 3 months of transplantation and $95 \%$ within 2 years. ${ }^{4}$ BKVN may present as asymptomatic acute or gradual deterioration of graft function, with graft loss reported as varying between 0 to $90 \%$ of cases in various series. ${ }^{5}$

A plasma BKV viral load of $>10,000$ copies $/ \mathrm{ml}$, detected by polymerase chain reaction (PCR), has a high positive predictive value of BKVN, and is termed "Presumptive BKVN". ${ }^{3}$ The diagnosis of "Definite BKVN" requires a graft biopsy.

The present study was carried out to evaluate the burden of definite BKVN in a single renal transplant centre in Australia.

\section{METHODS}

Study type and population: This was a single centre retrospective study. A total of 317 renal transplants, including simultaneous pancreas kidney (SPK) transplants, were performed in the centre over a period of 4 years from January 2010 to December 2013. A retrospective analysis of these patients was undertaken to identify biopsy proven BKVN. Biopsies performed for any reasons were included until December 2014. The study protocol was approved by the local Human Research Ethics Committee.

Data collection: Patients were followed up until December 2014. Recipient characteristics analysed included: age; gender; primary renal disease; mode of renal replacement therapy prior to transplantation and type of transplant performed. Factors potentially associated with BKVN that were examined included: number of Human Leucocyte Antigen (HLA) mismatches; pre-transplant antibody desensitization protocol; biopsy proven rejection episodes and additional immunosuppression for rejection prior to BKVN diagnosis; time from transplant to BKV viremia and to peak of BKV viremia; peak viral load; and time to clearance of viremia. Time from transplant to BKVN, concomitant acute rejection with BKVN on biopsy, treatment for BKVN, and rejection episodes post BKVN were recorded. Graft function [estimated glomerular filtration rate (eGFR)] was assessed at baseline which was defined as stable renal function within the first 3 post-transplant months and compared with that at the onset of BKV viremia, BKVN diagnosis and 3 and 12 months post-diagnosis. eGFR was calculated using the CKD-EPI formula. Graft failure was defined as the need for initiation of maintenance dialysis.

Immunosuppressive protocol: The centre's immunosuppressive protocol consists of induction with the interleukin-2 receptor antagonist, basiliximab $(20 \mathrm{mg}$, days 0 and 4) and tacrolimus, mycophenolate mofetil (MMF), and prednisolone maintenance. All patients received methylprednisolone $1 \mathrm{gm}$ on day 0 , and $500 \mathrm{mg}$ on day 1 followed by oral prednisolone $20 \mathrm{mg}$ daily. Prednisolone was tapered 6 weeks after transplantation by $2.5 \mathrm{mg}$ fortnightly to $5 \mathrm{mg}$ daily which was continued indefinitely. Mycophenolate was commenced at 2 grams a day in divided doses and then reduced to 1.5 grams a day by 6 months post-transplant. An oral loading dose of Tacrolimus $(0.1 \mathrm{mg} / \mathrm{kg})$ was given pre-operatively with a maintenance dose of $0.75 \mathrm{mg}$ twice daily adjusted to achieve a 12 hour trough level (Co) of $8-10 \mathrm{ng} / \mathrm{mL}$ during the first 3 months, 6-8 ng/mL at 3-6 months, and 3-6 $\mathrm{ng} / \mathrm{mL}$ thereafter.

High immunological risk patients [recipients with anti-HLA donor specific antibodies (DSAb) or ABO incompatible] received multiple sessions of plasmaphoresis (PEx) and low-dose intravenous immunoglobulins (IVIg), $0.1 \mathrm{mg} /$ $\mathrm{kg}$ body weight, (PEx/IVIg), perioperatively as part of a desensitization protocol.

All RTRs received: Pneumocystis jirovecii prophylaxis with trimethoprim-sulphamethoxazole (TMP/SMX, 160/800 $\mathrm{mg}$, twice weekly) for one year; CMV prophylaxis with valgancyclovir for 3-6 months and fungal prophylaxis with nystatin suspension and amphotericin lozenzes for 1 month.

Graft biopsy and diagnosis of BKVN and BKV viremia: Graft biopsies were performed whenever the fall in serum creatinine level in the post-operative period was not as expected and for unexplained sustained rises in serum creatinine. Surveillance biopsies were performed in all consenting patients at 3 and 12 months post-transplant. Allograft biopsies were scored in accordance with Banff'2007 criteria. $^{6}$

The diagnosis of BKVN on graft biopsy was made on the basis of positive immunoperoxidase staining for the simian virus 40 large T-antigen (SV-40), with or without virus mediated renal tubular epithelial cell damage and corresponding inflammation. ${ }^{3,7-10}$ However, grading of the histological lesion was not done..$^{5,10-12}$

Polymerase chain reaction (PCR) assays of plasma for BKV routinely in all RTRs were protocolled and additional assays were undertaken in patients with BKVN. Not all patients were screened by PCR according to protocol; however. Quantitative PCR had a detection limit of 1000 copies/ $\mathrm{ml}$. Two consecutive measurements less than this was considered as clearance of viremia. Presumptive BKVN 
(BKV viral load $>10000$ copies/ml but negative SV-40 stain and no viral cytopathic changes on graft biopsy) were not included in the study.

Management of BKVN: Immunosuppression was reduced in all patients on diagnosis of definite and presumptive BKVN. In general, both the mycophenolate and tacrolimus were reduced by $25-50 \%$ to keep mycophenolate $\leq 1 \mathrm{gm} /$ day and tacrolimus levels $<6 \mathrm{ng} / \mathrm{ml}$. The prednisolone dose was reduced to $<10 \mathrm{mg}$ daily. Additionally, high dose IVIg (1 $\mathrm{gm} / \mathrm{kg} / \mathrm{month}$ ) for 3-9 months was given to patients with concomitant acute antibody mediated rejection or significant graft dysfunction at the time of BKVN diagnosis. Treatment response was monitored by serial measurements of BKV viral load, eGFR, and repeat allograft biopsy when clinically indicated.

Statistical analysis: Data were expressed as mean \pm standard deviation (SD). Mean values were compared by paired t-tests and $P$ value of $<0.05$ was considered as statistically significant. Data analysis was conducted using SPSS software (version 16.0).

\section{RESULTS}

Of the 317 transplants performed in the study period, 20 (6.3\%) were complicated by BKVN. Their mean age was $54.8 \pm 13.1$ years (range 26 to 70 ) and $13(65 \%)$ were male. Sixteen $(80 \%)$ received deceased donor transplants. All but one were primary transplants. Table 1 summarises the patients' baseline characteristics.

All RTRs, except one, received basiliximab induction agent and all received tacrolimus, mycophenolate and prednisolone maintenance therapy. Table 2 summarises the distribution of potential risk factors for BKVN amongst RTRs. Five RTRs (25\%) had pre-formed DSAb and received $\mathrm{PEx} / \mathrm{IVIg}$ pre and post-transplant. Nine recipients (45\%) experienced acute rejection before the diagnosis of BKVN. The rejection episodes were comprised of 4 acute antibody mediated rejection (AMR), 1 borderline AMR, 1 borderline acute cell mediated rejection (ACR), 2 mixed AMR and ACR, and 1 borderline AMR and ACR. Four (20\%) received pulse methylprednisolone and $8(40 \%)$ received (PEx/IVIg) for 2-4 weeks. A single $500 \mathrm{mg}$ dose of rituximab was given to two patients for refractory AMR.

The mean time from transplant to onset of BKV viremia was $6.7 \pm 7.0$ months (range 2.2 to 33 ), as shown in table 3. Eighteen (90\%) recipients developed BKV viremia within 12 months of the transplant. The mean Peak BKV viral load was $23,845,476 \pm 55,578,126$ copies/ml, and was observed $8.7 \pm 7.0$ months (range 2.2 to 34 ) post-transplant. BKVN was diagnosed on average $8.7 \pm 6.7$ months (range 2.2 to 32.2) post-transplant, most (17 (85\%) within 12 months of transplant.

Five recipients (25\%) had acute rejection concomitant with BKVN on graft biopsy, 2 had mild AMR, 2 had mixed AMR and $A C R$, and 1 borderline AMR.
Table 1. Baseline transplant characteristics of BK nephropathy cases

\begin{tabular}{|c|c|}
\hline Characteristic & Mean \pm SD or number $(\%)$ \\
\hline \multicolumn{2}{|l|}{ Recipients } \\
\hline Age (years) & $54.8 \pm 13.1$ (range 26 to 70$)$ \\
\hline $\operatorname{Sex}(M / F)$ & $13 / 7(65 / 35)$ \\
\hline \multicolumn{2}{|l|}{ Primary Renal Disease: } \\
\hline Glomerulonephritis & $7(35)$ \\
\hline Diabetes mellitus type 2 & $2(10)$ \\
\hline Diabetes mellitus type 1 & $1(5)$ \\
\hline Hypertension & $2(10)$ \\
\hline ADPKD & $4(20)$ \\
\hline Reflux Nephropathy & $2(10)$ \\
\hline Miscellaneous & $2(10)$ \\
\hline \multicolumn{2}{|l|}{ Mode of RRT before the transplant } \\
\hline In centre Hemodialysis & $8(40)$ \\
\hline Home Hemodialysis & $4(20)$ \\
\hline CAPD & $4(20)$ \\
\hline APD & $4(20)$ \\
\hline \multicolumn{2}{|l|}{ Donors } \\
\hline Age (years) & $54.8 \pm 13.1$ (range 26 to 70$)$ \\
\hline Sex (M/F) & $13 / 7(65 / 35)$ \\
\hline \multicolumn{2}{|l|}{ Type of transplant: } \\
\hline Donor brain death & $14(70)$ \\
\hline Donor circulatory death & $1(5)$ \\
\hline Live related donor & $2(10)$ \\
\hline Live unrelated donor & $2(10)$ \\
\hline Simultaneous Pancreas Kidney & $1(5)$ \\
\hline $\begin{array}{l}\text { M, Male; F, Female; } \\
\text { ADPKD, Adult Polycystic Kidney } \\
\text { CAPD, Continuous Ambulatory P } \\
\text { APD, Automated Peritoneal Dialy }\end{array}$ & eal Dialysis; \\
\hline
\end{tabular}

Table 2. Factors associated with the development of BKVN

\begin{tabular}{|ll|}
\hline Characteristic & N (\%) \\
\hline HLA mismatches: & \\
\hline 2 mismatches & $6(30)$ \\
\hline 3 mismatches & $3(15)$ \\
\hline 4 mismatches & $3(15)$ \\
\hline 5 mismatches & $5(25)$ \\
\hline 6 mismatches & $3(15)$ \\
\hline Desensitization with PEx + IVIg & $5(25)$ \\
\hline BPAR prior to BKVN & $9(45)$ \\
\hline BPAR treatment prior to BKVN: & \\
\hline Pulse methylprednisolone & $4(20)$ \\
\hline PEx + IVIg & $8(40)$ \\
\hline Rituximab & $2(10)$ \\
\hline $\begin{array}{l}\text { HLA, Human Leucocyte Antigen; } \\
\text { PEx, Plasmaphoeresis; } \\
\text { IVIg, BPAR, biopsy proven acute rejection; Intravenous Immunoglobulins; } \\
\text { DSAb, Donor specific antibodies; } \\
\text { BKVN, BK virus associated nephropathy }\end{array}$ \\
\hline
\end{tabular}


Table 3. BKV viremia and BKVN in renal transplant recipients

\begin{tabular}{|c|c|}
\hline Characteristic & Mean \pm SD / N (\%) \\
\hline Time from transplant to BKV viremia & $\begin{array}{l}6.7 \pm 7.0 \text { months } \\
\text { (range } 2.2 \text { to } 33 \text { ) }\end{array}$ \\
\hline Onset of BKV viremia $<6$ months post-Tx & $14(70)$ \\
\hline Onset of BKV viremia 6 to 12 monthspost-Tx & $4(20)$ \\
\hline Onset of BKV viremia $>12$ months post-Tx & $2(10)$ \\
\hline Peak BKV viral load & $\begin{array}{l}23,845,476 \pm \\
55,578,126 \text { copies } / \mathrm{ml}\end{array}$ \\
\hline Time from Tx to peak BKV viral load & $\begin{array}{l}8.7 \pm 7.0 \text { months } \\
\text { (range } 2 \text { to } 34 \text { ) }\end{array}$ \\
\hline Time from Tx to BKVN & $\begin{array}{l}8.7 \pm 6.7 \text { months } \\
\text { (range } 2 \text { to } 32 \text { ) }\end{array}$ \\
\hline BKVN $<6$ months post-Tx & $9(45)$ \\
\hline BKVN 6 to 12 months post-Tx & $8(40)$ \\
\hline BKVN >12 months post-Tx & $3(15)$ \\
\hline Concomitant acute rejection with BKVN & $5(25)$ \\
\hline Acute rejection after IS reduction for BKVN & $2(10)$ \\
\hline $\begin{array}{l}\text { BKV, BK virus; } \\
\text { Tx, Transplant; } \\
\text { BKVN, BK virus associated nephropathy; } \\
\text { IS, Immunosuppression }\end{array}$ & \\
\hline
\end{tabular}

All cases of BKVN were treated with immunosuppression reduction. High dose IVIg was given to 13 (65\%) recipients because of concomitant AMR or graft dysfunction or both.

Following immunosuppression reduction \pm high dose IVIg, 10 recipients $(50 \%)$ had clearance of BKV viremia after an average of $12.2 \pm 11.6$ months (range 1.1 to 33.0). Only $4(20 \%)$ achieved viral clearance within 6 months. Ten recipients (50\%) did not have viral clearance after $24.2 \pm$ 10.7 months (range 9 to 41) follow-up.

Figure 1 shows eGFR at different time points after transplant. The baseline eGFR was $50.3 \pm 16.4 \mathrm{ml} / \mathrm{min} / \mathrm{m}^{2}$ (range 23 to 85 ). eGFR at the onset of BKV viremia and at the time of BKVN were $44.8 \pm 18.6$ (range 18 to 85 ), and $38.8 \pm 19.2$ (range 14 to 81 ) $\mathrm{ml} / \mathrm{min} / \mathrm{m}^{2}$ respectively, which were significantly different ( $p<0.02$ and $<0.01$ respectively) from the baseline eGFR. Mean eGFR improved numerically at 3 and 12 months after BKVN, eGFR were $42.3 \pm 19.2$ (range 10 to 77 ), and $43.9 \pm 19.1$ (range 9 to 75 ) $\mathrm{ml} / \mathrm{min}$ / $\mathrm{m}^{2}$ respectively; however these differences were not statistically significant.

Two recipients (10\%) developed acute rejection that was temporally related to the reduction in immunosuppression following BKVN. One rejection episode was acute AMR and another was mixed acute AMR and borderline ACR. Both cases were treated with high dose IVIg monthly for 6 months. Their eGFR in the last follow up in December 2014 were 25 and $27 \mathrm{ml} / \mathrm{min} / 1.73 \mathrm{~m}^{2}$ respectively.

One patient $(5 \%)$ had graft failure 19 months after the diagnosis of BKVN. This patient was a 61 year old male, who had received a deceased donor transplant from a 74 year old male. He developed acute tubular necrosis (ATN) post-

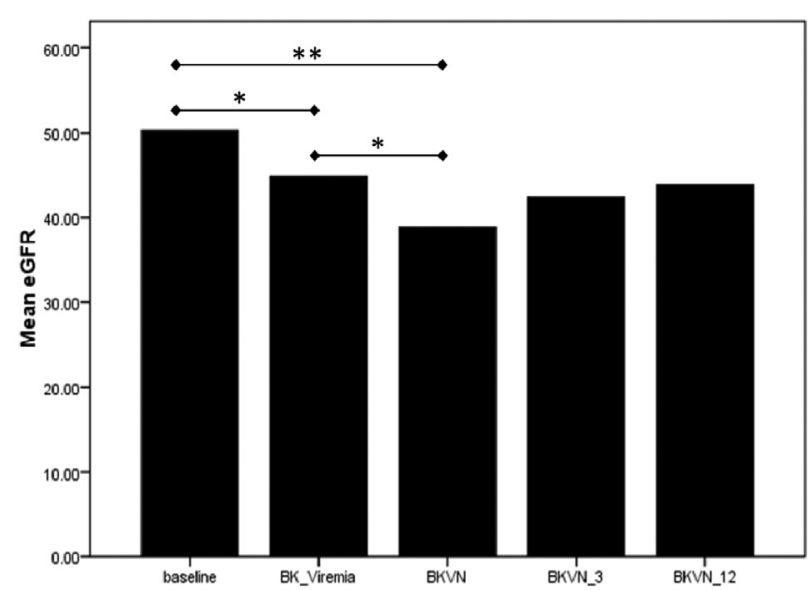

Figure 1. Graft function at different time points after transplant

Baseline stable renal function in first 3 months of transplant;

BK_Viremia, graft function at the onset of BKV viremia;

BKVN, graft function at BK virus associated nephropathy (BKVN);

BKVN_3, graft function at 3 months post-BKVN;

BKVN_12, graft function at 12 months post BKVN.

*P value $<0.02 ; * *$ P value $<0.01$

transplant and had a baseline creatinine of $252 \mu \mathrm{mol} / \mathrm{ml}$ (eGFR $23 \mathrm{ml} / \mathrm{min} / 1.73 \mathrm{~m}^{2}$ ). Ten months post-transplant he was diagnosed with BKVN, when a graft biopsy was done for an increase in serum creatinine to $370 \mu \mathrm{mol} / \mathrm{ml}$ (eGFR $\left.14 \mathrm{ml} / \mathrm{min} / 1.73 \mathrm{~m}^{2}\right)$, on the background of BKV viremia. Despite immunosuppression reduction and use of high dose IVIg monthly for 3 months, the BKV viremia persisted and he progressed to end stage renal failure. He was initiated on maintenance hemodialysis when graft function deteriorated to reach an eGFR of $8 \mathrm{ml} / \mathrm{min} / 1.73 \mathrm{~m}^{2}$.

There was no mortality during the study period.

\section{DISCUSSION}

The incidence of biopsy proven BKVN in our study was 6.3\%. Previous studies have reported BKVN in 1-10\% of the kidney transplant recipients. ${ }^{3,5,12}$ The primary risk for the development of BKV infection in renal transplant recipients is the intensity and cumulative exposure to immunosuppression. ${ }^{5}$ Use of lymphocyte depleting antibodies, cumulative corticosteroid exposure, TacolimusMMF based maintenance immunosuppression, higher immunosuppressive drug levels are some of the reported immunosuppression related risk factors. ${ }^{5,12}$ Recently pretransplant desensitization with PEx/IVIg has shown to increase the risk for BKV viremia and nephropathy. ${ }^{13}$

Recipient risk factors including older age, male sex and donor related risk factors including female sex, active BKV and cytomegalovirus infection and deceased donor transplant are also thought to influence BKV infection., ${ }^{5,12}$ In our study all recipients were on tacrolimus-mycophenolate based immunosuppression, a large proportion were elderly males who had received deceased donor transplants, and had additional immunosuppression either in the form of 
a desensitization protocol or for the treatment of acute rejection episodes before the diagnosis of BKVN.

Previous studies have reported that most (95\%) BKVN occurs in the first 2 years after transplantation. ${ }^{3,4,12}$ In our study the mean time from transplant to BKVN was $8.7 \pm$ 7.0 months and $85 \%$ of cases were diagnosed within 12 months of transplantation. Four recipients each in our study were diagnosed with BKVN on 3 and 12 month protocol biopsies in spite of stable serum creatinine levels. This emphasizes the clinical utility of surveillance biopsies in detecting subclinical BKVN with the possibility of reducing future injury by allowing timely modification of immunosuppression. Indeed, in the study by Christopher et al. which compared transplant outcomes in groups randomised to surveillance biopsies compared with no surveillance biopsies, $45 \%$ of BKVN cases were diagnosed on surveillance biopsy with the surveillance biopsy group more likely than the no surveillance group to have better graft status at 6 months. ${ }^{14}$

In our study only one recipient (5\%) had graft failure during the study period. Though the improvement in mean eGFR at 3 and 12 months post BKVN was not statistically significant, it indicated stabilization of graft function in most patients. Progressive allograft failure has previously been reported in approximately $30-60 \%$ of BKVN cases from older studies. ${ }^{15}$ However, in more recent studies, improvement or stabilization of graft function occurred in a greater proportion of recipients. ${ }^{16,17}$ Increased awareness of BKV infection among renal transplant physicians and pathologists, surveillance biopsies (as discussed above), monthly monitoring of BKV viremia and pre-emptive reduction of immunosuppression on detection of BKV viremia have played an important role in improved outcomes of BKVN. ${ }^{4,5}$

Classification of the histological pattern of BKVN into categories A, B, C, and sub classification of B in to b1, b2 and b3 correlates with graft outcome. ${ }^{5,10-12}$ Stage $A$ consists of mild viral cytopathic changes with minimal interstitial inflammation $(<10 \%)$; stage $B$ includes variable viral cytopathic changes and b1: moderate (11$25 \%)$ interstitial inflammation, b2: significant (26-50\%) interstitial inflammation, b3: extensive (>50\%) interstitial inflammation; and stage $\mathrm{C}$ consists of variable viral cytopathic changes with extensive ( $>50 \%)$ tubular atrophy/ interstitial fibrosis. ${ }^{5}$ Stage A generally has a good prognosis whilst stage $B$ and $C$ are more likely to progress to chronic allograft dysfunction. We do not currently grade the severity of BKVN by this schema however we will look to do so to increase standardization and comparability of the reports. This is one of the limitations of the current study.

BKVN can mimic acute rejection and can often coexist. ${ }^{5,12}$ Because tubulointerstitial rejection can look like BKVN, additional findings of AMR such as endarteritis, glomerulitis, peritubular capillaritis and $\mathrm{C} 4 \mathrm{~d}$ staining of peritubular capillaries should be sought. Immunoperoxidase staining with SV40, another member of the Papovaviridae family (simian form of Polyomavirus), cross-reacts with BKV and confirms the diagnosis of BKVN as opposed to acute rejection. ${ }^{18}$ In our study 5 (25\%) of the recipients had concomitant AR with BKVN, and all of them had coexisting changes of acute AMR.

Approximately, $50 \%$ of RTRs who develop BKV viremia do so by 3 months after transplant and BKV viremia generally precedes BKVN by a median of 8 weeks. ${ }^{4,12}$ Hence screening for BKV replication should be started early after transplant. Kidney Disease Improving Global Outcomes (KDIGO) guidelines suggest screening all RTRs for BKV with quantitative plasma PCR at least monthly for the first 3-6 months after transplantation, then every 3 months until the end of the first post-transplant year and whenever there is an unexplained rise in serum creatinine, and after treatment for acute rejection. ${ }^{4}$ The guidelines also recommend reduction of immunosuppression when BKV viral load exceeds 10000 copies/ml, even in the absence of histological changes of BKVN (presumptive BKVN). ${ }^{4}$ In our transplant program BKV DNA PCR was planned to be performed at least 3 monthly however this schedule was not adhered to in all patients. Additionally, cases of BKVN may have been missed as biopsies were not performed on all patients with BKV viremia. These 2 limitations mean that the true incidence of BKV viremia and BKVN may have been greater than those reported.

Reducing the intensity of maintenance immunosuppression is the primary mode of intervention for both presumptive and definitive BKVN. ${ }^{12,19,20}$ Several protocols have been proposed which include reduction, discontinuation or switching of an agent within the same class or to another class. ${ }^{12}$ Adjuvant therapy with antiviral drugs like cidofovir, leflunomide, intravenous immunoglobulins and quinolone antibiotics has been attempted with variable results. ${ }^{12}$ However, concomitant reduction of immunosuppression makes it difficult to interpret whether a positive response is due to a particular agent or of the immunosuppression reduction. ${ }^{21}$ We reduced immunosuppression in all our patients on diagnosis of BKVN, and used IVIg along with immunosuppression reduction in 13 (65\%) patients. However, we did not compare the outcome of recipients who did or did not receive IVIg, because IVIG in our study was generally used for patients who had either acute rejection concomitant with BKVN or more significant graft dysfunction.

\section{CONCLUSION}

In conclusion, this study, in accordance with the previous studies, showed that BKVN commonly manifests in first year of renal transplant and constitutes an important cause of early graft dysfunction. A substantial proportion of BKVN was detected on 3 and 12 months surveillance biopsies 
with normal graft function, and might be responsible for the excellent graft survival seen in our patients relative to previous reports.

\section{ACKNOWLEDGEMENTS}

We would like to acknowledge the International Society of Nephrology (ISN) for sponsoring Shailendra Shrestha as an ISN fellow at the Department of Nephrology, Monash Medical Centre, Melbourne, Australia, for one year. Apart from that the authors do not have any other financial disclosure related to the article and no conflict of interest. We would also like to thank Orla Maney, Elaine Kennedy, Tia Mark and Sally Watts, Kidney and Pancreas Transplant Office, Department of Nephrology, Monash Medical Centre, for generously helping us in data collection for the study.

\section{REFERENCES}

1. Gardner SD, Field AM, Coleman DV, Hulme B. New human papovavirus (B.K.) isolated from urine after renal transplantation. Lancet 1971; 1 : 1253- 1257.

2. Kean JM, Rao S, Wang M, Garcea RL. Seroepidemiology of human polyomaviruses. PLoS Pathog 2009; 5 (3): e1000363.

3. Hirsch HH, Knowles W, Dickenmann M, et al. Prospective study of polyomavirus type BK replication and nephropathy in renal transplant recipients. N Engl J Med. 2002; 347: 488-496.

4. Kidney Disease: Improving Global Outcomes (KDIGO) Transplant Work Group. KDIGO clinical practice guideline for the care of kidney transplant recipients. American Journal of Transplantation. 2009; 9(Suppl 3): S1-S157.

5. Hirsch HH, Randhawa P. AST Infectious Diseases Community of Practice: BK Polyomavirus in Solid Organ Transplantation. American Journal of Transplantation. 2013; 13: 179-188.

6. Solez K, Colvin RB, Racusen LC, et al. Banff 07 classification of renal allograft pathology: updates and future directions. Am J Transplant. 2008; 8(4): 753-60.

7. Drachenberg CB, Beskow $\mathrm{CO}$, Cangro $\mathrm{CB}$ et al. Human polyomavirus in renal allograft biopsies: Morphological findings and correlation with urine cytology. Hum Pathol. 1999; 30: 970-977.

8. Randhawa PS, Demetris AJ. Nephropathy due to polyomavirus type BK. N Engl J Med. 2000; 342:1361-1363.

9. HirschHH: PolyomavirusBKnephropathy: $\mathrm{A}$ (re-)emerging complication in renal transplantation. Am J Transplant. 2000; 2: 25-30.

10. Drachenberg RC, Drachenberg CB, Papadimitriou JC et al. Morphological spectrum of polyoma virus disease in renal allografts: Diagnostic accuracy of urine cytology. Am J Transplant. 2001; 1: 373381.

11. Drachenberg CB, Papadimitriou JC, Hirsch HH, et al. Histologic patterns of polyomavirus nephropathy: Correlation with graft outcome and viral load. Am J Transplant. 2004; 4: 2082-2092.

12. Hirsch HH, Brennan DC, Drachenberg CB et al. Polyomavirus associated nephropathy in renal transplantation: interdisciplinary analyses and recommendations. Transplantation 2005;79(10):1277-86.

13. Gabardi S, Townsend K, Martin ST, Chandraker A. Evaluating the impact of pre-transplant desensitization utilizing a plasmapheresis and low dose intravenous immunoglobulin protocol on BK viremia in renal transplant recipients. Transplant Infectious Disease 2013;15: 361-368.

14. Christopher KB, Donna JL, Mark DS, et al. Influence of surveillance renal allograft biopsy on diagnosis and prognosis of polyomavirusassociated nephropathy. Kidney International. 2003; 64: 665-73.

15. Hariharan S. BK virus nephritis after renal transplantation. Kidney International. 2006; 69: 655-62.

16. Drachenberg CB, Papadimitriou JC, Wali R et al. Improved outcome of polyoma virus allograft nephropathy with early biopsy. Transplant Proc. 2004; 36: 758-9.

17. Vasudev B, Hariharan S, Hussain SA et al. BK virus nephritis: Risk factors, timing, and outcome in renal transplant recipients. Kidney International. 2005; 68: 1834-9.

18. Dall A and Hariharan S. BK Virus Nephritis after Renal Transplantation. Clin J Am Soc Nephrol. 2008; 3: 68-75.

19. Ramos E, Drachenberg CB, Wali R, Hirsch $\mathrm{HH}$. The decade of polyomavirus BK-associated nephropathy: state of affairs. Transplantation. 2009;87(5):621-30.

20. Schaub S, Hirsch HH, Dickenmann $M$ et al. Reducing Immunosuppression Preserves Allograft Function in Presumptive and Definitive Polyomavirus-Associated Nephropathy. American Journal of Transplantation. 2010; 10: 2615-23.

21. Johnston O, Jaswal D, Gill JS, et al. Treatment of polyomavirus infection in kidney transplant recipients: a systematic review. Transplantation. 2010; 89 (9): 1057-70. 